\title{
Edukacja w zakresie \\ przedsiębiorczości na poziomie \\ akademickim w Republice Korei ${ }^{1}$
}

DOI: 10.47050/65591760.316-327

Julita Majczyk

Systemy edukacji na poziomie międzynarodowym są zróżnicowane, zaprojektowane tak, by spełniać oczekiwania stawiane przez otoczenie ekonomiczne, kulturowe czy społeczne. Przykładem zmian w edukacji na poziomie akademickim jest Republika Korei, w której otoczenie polityczne wyznaczyło szkoły przedsiębiorczości, których celem jest wspieranie rozwoju gospodarczego. Jednak uniwersytet nie jest jedyną instytucją promującą działania przedsiębiorcze. W artykule scharakteryzowano wybrane elementy ekosystemu przedsiębiorczości.

\section{Słowa kluczowe:}

edukacja przedsiębiorczości

kompetencje

konkurencja

program nauczania

intencja przedsiębiorcza

1. UE: This project has received funding from the European Union's Horizon 2020 research and innovation programme under the Marie Skłodowska-Curie grant agreement No 734824. MNiSW: Scientific paper funded from financial sources for science in the years 2017-2020 awarded for the implementation of the international co-financed project. 


\section{Entrepreneurship education at the tertiary level in the Republic of Korea}

DOI: 10.47050/65591760.316-327

Julita Majczyk

Diversified Educational Systems at the international level are designed to meet economic, cultural, or social expectations. The Republic of Korea, where the political environment designated entrepreneurship schools that aim to support economic development, is an example of changes introduced in education at the academic level. However, the university is not the only institution that promotes entrepreneurial activities. The article describes selected elements of the entrepreneurship ecosystem.

\section{Keywords:}

entrepreneurship education

\section{competences}

competition

study program

entrepreneurial intention 


\section{Wstęp}

Siłą napędową koreańskiej gospodarki są szkolnictwo i przedsiębiorczość. Od 1960 do 2017 r. PKB wzrósł niemal sześciokrotnie, PKB per capita (według parytetu siły nabywczej) w 2017 r. wynosił 38,3 tys. dol. Dla porównania w Polsce -29 tys. dol. Do wzrostu popularności działań przedsiębiorczych w Republice Korei przyczynia się rząd, który wskazuje kierunek dalszego rozwoju. W ramach ogłoszonego w sierpniu 2017 r. planu pięcioletniego przygotowanego przez administrację obecnego prezydenta Republiki Korei, Mun Jae-ina, podjęto się promowania ekosystemu przedsiębiorczego, w tym rozwoju kreatywnych startupów i kształtowania innowacyjnych przedsiębiorców. Promowane są wszystkie próby podejmowania działań przedsiębiorczych. Bez względu na właściciela procesu przedsiębiorczego, skali działań czy zasięgu prowadzonej aktywności.

\section{Wybrane aspekty kultury koreańskiej}

Cechą charakterystyczną kultury koreańskiej jest nieustanne konkurowanie już na poziomie indywidualnym. Konkurują ze sobą rodzice, przykładowo o to, do jakiej szkoły zapisać dziecko, jaką wyprawkę szkolną zorganizować, konkurują ze sobą dzieci. Praca w zespole, pojęcie współpracy opartej na zaufaniu właściwie nie funkcjonują, z uwagi na społecznie akceptowalną postawę skoncentrowaną na wynikach indywidualnych, tj. nieustającej konkurencji. System ocen na poziomie akademickim podtrzymuje tę konwencję poprzez egzekwowanie od wykładowców oceny studentów w myśl rozkładu normalnego.

Wskaźnik samobójstw i wskaźnik spożycia alkoholu są na wysokim poziomie, co tłumaczy się niskim poziomem zadowolenia z życia, pomimo wysokich zarobków. I choć subiektywna satysfakcja z życia poprawiła się w ostatniej dekadzie, nadal jest poniżej średniej krajów OECD (2017b, s. 263). Opisując charakterystyczne cechy społeczeństwa, Koreańczycy te wskaźniki często przywołują razem. Jednak spożycie alkoholu najwyższe jest na Litwie, wyższe od Republiki Korei jest także w Polsce. Litwa zajmuje pierwsze miejsce, Polska-12., a Korea- 23. (OECD, 2018a). Jeśli chodzi o wskaźnik samobójstw, to Koreańczycy zajmują drugą lokatę zaraz po Litwinach (OECD, 2018b). W 2015 r. na 100 tys. osób Koreańczycy popełnili 25,8 samobójstw. Dla porównania w Polsce wskaźnik ten wynosi 13,5.

W Republice Korei występuje także zjawisko dyskryminacji płciowej, choć ma być zwalczane, przykładowo regulacjami prawnymi, 
które mają determinować obecność kobiet w organach zarządczych przedsiębiorstw. W organizacjach powszechne jest zwalnianie kobiet, które urodziły dziecko. W innych przypadkach doradza się kobietom dobrowolną rezygnację z pracy np. przed 35. rokiem życia, ponieważ przyjmuje się, że po tym okresie chciałyby mieć one już dzieci. Stąd zakładanie przedsiębiorstw jest z jednej strony szansą na realizację pomysłów i wykorzystanie kompetencji, z drugiej zapobiega bezrobociu, pozwala także na pracę $w$ dowolnym czasie. Celem poprawy warunków pracy na etacie w 2018 r. zarządzono maksymalnie 52-godzinowy tydzień pracy, jednak w weekendy pozwala się na więcej przepracowanych godzin.

\section{Narzędzia rozwoju przedsiębiorczości}

Zmiany w otoczeniu gospodarczym znajdują swoje odzwierciedlenie także w strukturze instytucjonalnej. Agencję rządową stworzoną dla małych i średnich przedsiębiorstw (ang. Small and Medium Business Administration, SMBA), którą nadzorowało Ministerstwo Handlu, Przemysłu i Energii, odpowiadające przede wszystkim za regulowanie polityki gospodarczej, w 2017 r. zastąpiło Ministerstwo MSP i Start-upów. Przez 21 lat SMBA wspierała innowacje po stronie MSP jako katalizatora wzrostu gospodarki narodowej, dążąc przy tym do ich stabilnego rozwoju. Obecny rząd zamierza dalej wyzwalać potencjał przedsiębiorczy młodych ludzi.

Do narzędzi wspierających należą: programy dla młodzieży pomagające w wyborze ścieżki kariery i rozwoju ich aktywności przedsiębiorczej, inkubatory przedsiębiorczości przy uniwersytetach i innych instytucjach badawczych, szkolenia i kluby stratupowe, szkoły biznesu i programy dla start-upów uruchamiane w całym kraju (Sahay i Sharma 2008, s. 166-167). Przykładowym programem jest Youth Start-up Academy uruchomiony w 2011 r. dla potencjalnych przedsiębiorców poniżej 39. roku. Studenci nabywają wiedzę z zakresu budowania podmiotu gospodarczego, otrzymują częściowe finansowanie poniesionych kosztów związanych z jego rozwojem, szkoleni są przez specjalistów-praktyków biznesu, a także otrzymują narzędzia i przestrzeń do pracy. Kolejnym narzędziem jest współpraca rządowa z dużymi przedsiębiorstwami, czego efektem są projekty, które upowszechniają wiedzę z zakresu budowania sklepów internetowych czy promowania produktów, np. E-commerce Dream Project dużego portalu Naver. 
Koreańczycy, którzy nauczeni są konkurowania, mają okazję brać udział także w corocznym konkursie budowania przedsięwzięcia biznesowego - K-start-up Contest, w którym łącznie można wygrać pół miliona dolarów, zdobyć kontakty biznesowe i skupić na sobie uwagę mediów.

Inkubatory zapewniają usługi doradcze w zakresie funkcjonowania podmiotów gospodarczych. W grudniu 2017 r. zanotowano ponad 206 tys., które przetrwały pięć lat, natomiast ponad 520 tys. start-upów funkcjonowało na rynku przez rok, z czego 91,5 proc. miało założycieli indywidualnych, a 8,5 proc. pozostałych podmiotów założyły spółki. Struktura wykształcenia założycieli start-upów pokazuje, że najwięcej, niemal 38,3 proc., ukończyło licencjat, około 36,2 proc. szkołę średnią, a niecałe 11 proc. ma wykształcenie niższe niż średnie (Statista 2018). Przykładem inkubatora jest choćby Aspirin Incubation Center, które również zapewnia przestrzeń do pracy, pomaga w rozwiązywaniu problemów i promuje programy rozwoju. Największym inkubatorem jest Seoul Startup Hub. Do jego głównych działań należą: networking, badania rynku, program inkubacji, edukacja i konsulting (Seoul Startup Hub, 2017). Celem networkingu jest umożliwienie nawiązania stosunków między start-upami, inwestorami, akceleratorami, interesariuszami i ekspertami przykładowo od marketingu czy podatków. Badania obejmują analizy ekosystemu przedsiębiorczości, w tym wielkości podmiotów, analizy profilu uczestników ekosystemu, infrastruktury, trendów biznesowych i benchmarking, które mają przełożyć się na aktywne współtworzenie otoczenia prawno- politycznego. Program inkubacji polega na ćwiczeniu prezentacji sprzedażowych dla potencjalnych inwestorów. Edukacja obejmuje 75 godzin wykładów specjalizacyjnych ukierunkowanych na budowanie i rozwój podmiotów gospodarczych na poziomie podstawowym i od sześciu do dziewięciu godzin ćwiczeń praktycznych z marketingu, projektowania i finansów. Kurs globalny przeznaczony jest dla przedsiębiorców, którzy chcą działać na skalę międzynarodową, a ich celem jest nabycie kluczowych kompetencji, które mają im to umożliwić. Program oferuje także zajęcia w obszarze projektowania i rozwoju aplikacji internetowych oraz przemawiania. W ramach konsultacji można uzyskać porady od ekspertów z dziedziny prawa, zasobów ludzkich, technologii, marketingu, praw własności intelektualnej, start-upów czy zarządzania. 


\section{Edukacja na poziomie akademickim}

Agencja rządowa SMBA zapoczątkowała także działalność szkół przedsiębiorczości w strukturze uniwersytetów. Ministerstwo je wspiera, aby zapewnić edukację w zakresie przedsiębiorczości systemowo. Celem szkół jest z kolei rozwój ekspertów start-upów, którzy wykażą się elastycznością w działaniu, umożliwiającym adaptację do zmian w otoczeniu. Zaprojektowane kursy i wybrane metody kształcenia mają nauczyć studentów identyfikowania luki rynkowej i podejmowania ryzyka. Przykładowymi uniwersytetami, które uruchomiły szkoły przedsiębiorczości, są: Hoseo University (Graduate School of Global Entrepreneurship), Chung-Ang University (Graduate School of Industrial and Entrepreneurial Management), Kookmin University (Graduate School of Global Entrepreneurship), Handong Global University (Global Entrepreneurship and Information, Communication Technology). W Hoseo University szkoła ma przypisany profil ogólny, natomiast w Chung-Ang i Kookmin University została ona skategoryzowana jako program specjalny. W Chung-Ang University wykłady i studia przypadków osadzono w problematyce administracji wiedzą, dystrybucji, zmian klimatycznych, zarządzaniu przedsiębiorczym, konsultingu przedsiębiorczym i globalnej franczyzie. Edukacja przedsiębiorczości w Kookmin University przeznaczona jest dla osób pracujących, które chcą założyć biznes. Oferowane są dwuletnie kierunki, takie jak inkubacja, edukacja i venture, które uzupełnione są o obowiązkowy staż. Praktyki przedsiębiorcze i wiedza przekazywane są przez wykładowców akademickich, przedsiębiorców seryjnych, inwestorów kapitału podwyższonego ryzyka (ang. venture capital), aniołów biznesu, decydentów oraz regionalnych i krajowych liderów biznesu.

Soongsil University otworzył Zakład Przedsiębiorczości i Małego Biznesu w 1995 r., którego celem jest praktyczne uzupełnienie teoretycznych dyskusji. Tym samym prace tego zakładu koncentrują się na budowaniu szans rynkowych, tworzeniu nowych rynków, zróżnicowaniu produktów, akceleracji wzrostu podmiotów gospodarczych. Do najważniejszych przedmiotów należą: rachunkowość, statystyka, finanse przedsiębiorstw, przedsiębiorstwo społeczne, inwestycje podwyższonego ryzyka, rozwój przedmiotu działalności, wstęp, program i polityka dotycząca MSP, trening przedsiębiorczego start-upa, studia przypadku w marketingu, przedsiębiorczość globalna oraz praktyki przedsiębiorcze w sektorze usług. 
W Sookmyung Women's University w 2010 r. utworzono Zakład Zarządzania w ramach Szkoły Usług Globalnych (ang. School of Global Service), którego celem jest ukształtowanie liderów-założycieli podmiotów innowacyjnych i z wizją. Promowana jest innowacyjność oparta na kobiecej wrażliwości, emocjach, humanizmie i elastyczności wobec zmieniającego się otoczenia. Znajomość języków obcych traktuje się jako narzędzia poznania kultury, stąd przedmioty nauczane są w języku angielskim, co ma wspierać myślenie globalne, ale wymaga się także nauki japońskiego lub chińskiego, by lepiej zrozumieć rynek azjatycki. Wśród kompetencji wymienia się umiejętność planowania i wdrażania pomysłów na skalę globalną.

Handong Global University oferuje kierunek przedsiębiorczość globalna. Do kluczowych kompetencji absolwentów należą: postawa przedsiębiorcza, analiza problemowa rynku, planowanie projektowe, rozwój biznesu, rozwiązywanie problemów i rozwój przedmiotu działalności, a do podstawowych zagadnień tematycznych: budowa przedsiębiorstwa, badanie rynku, rachunkowość i inwestycje, marketing, prawo i etyka w biznesie.

Najstarszą, założoną w 1905 r. i jednocześnie najlepszą akredytowaną szkołą biznesu w Republice Korei jest Korea University Business School. Ceni się ją z uwagi na badania i edukację, ale i utożsamia z innowacyjnością. Charakteryzują ją silna sieć absolwentów z najwyższą notowaną liczbą dyrektorów generalnych i biegłych rewidentów księgowych. Szkoła otworzyła również Instytut Start-upów, który stanowi forum dyskusji i działań na rzecz innowacji, współpracy i dzielenia się zarówno wiedzą, jak i doświadczeniem. Jest centrum inkubacji przedsięwzięć biznesowych i dostarczania wiedzy. Do narzędzi promocji przedsiębiorczości należą konkurs dla start-upów, gdzie zwycięzcy mogą otrzymać finansowanie kosztów operacyjnych, sesje mentoringowe przykładowo w zakresie prawa, patentów czy marketingu, networking z inwestorami dostarczającymi kapitału wysokiego ryzyka i innymi przedsiębiorcami, przestrzeń do pracy indywidualnej i zespołowej, prowadzenie seminariów. W ramach oferowanego programu edukacyjnego serie wykładów na temat przedsiębiorczości i innowacji oraz treningi umiejętności prowadzą praktycy (KUBS 2014a). Na uniwersytecie dla studentów I stopnia utworzono Program Akademii Przedsiębiorczości (ang. Entrepreneurship Academy Program) ukierunkowany na ukształtowanie przedsiębiorców podejmujących działania stymulowane wy- 
zwaniami. Tematami podejmowanymi w procesie kształcenia są: technologia, społeczeństwo i kultura, a prowadzącymi są także wybrani dyrektorzy generalni podmiotów gospodarczych (KUBS 2014b).

Jeśli już utworzono opis kierunku w języku angielskim, to zaprezentowane w nim cele przyjęte przez wybrane uniwersytety rzadko kiedy się powtarzają. W badaniu przeprowadzonym przez Byun, Sung, Park i Choi wykazano, że do najważniejszych elementów w zakresie przekazywanej wiedzy o przedsiębiorczości i start-upach należą: szukanie szans rynkowych, opracowanie planów biznesowych i analizy wykonalności, budowanie biznesplanu, rachunkowość, finanse i marketing. Do pozostałych przedmiotów, które uważa się za istotne, można zaliczyć: kapitał podwyższonego ryzyka i przedsiębiorczość technologiczną, a także komercjalizację (Byun i in. 2018, s. 8). Dla studentów i absolwentów szkół przedsiębiorczości ważne są: sieć absolwentów, partnerstwo z instytucjami zewnętrznymi, mentoring i szkolenia zarówno w trakcie studiów, jak i po ich zakończeniu (Byun i in. 2018, s. 10). Docenia się także wizyty praktyków na zajęciach, a także prowadzenie ich przez doświadczonych instruktorów i nauczycieli, którzy zarządzają start-upem. Analiza130 ankiet studentów kierunku projektowanie biżuterii w badaniu Chang i Choi $(2018$, s. 2939) potwierdziła, że dla rozpoczęcia biznesu najważniejsze przedmioty w edukacji przedsiębiorczości to: marketing, finansowanie oraz networking, tj. nawiązywanie relacji, a także projektowanie oraz zarządzanie wiedzą. Potwierdzono również, że edukacja przedsiębiorczości pozytywnie wpływa przede wszystkim na intencje przedsiębiorcze, następnie na wzrost innowacyjności, wdrażanie kolejnych pomysłów, wrażliwość na ryzyko oraz rozwój sieci społecznej. Studenci podejmujący kurs przedsiębiorczości odnotowują wyższy poziom intencji przedsiębiorczych i wiary we własne możliwości - wyższy także od poziomu amerykańskich studentów, co prawdopodobnie tłumaczą kultura konkurowania i potrzeba osiągnięć (Lee i in. 2005 , s. 38). Otoczenie społeczne i ekonomiczne pozytywnie wzmacniają poziom motywacji oraz pewności siebie, a intencje budowania podmiotów są także remedium na ograniczone możliwości otrzymania miejsca pracy (Lee i in. 2006, s. 360).

Odpowiedzi udzielone podczas przeprowadzonych wywiadów jakościowych, które odbyły się w lipcu i listopadzie 2018 r. w Republice Korei, potwierdzają, że studenci, którzy nie kończą kierunku przedsiębiorczość, nie zdobywają wiedzy praktycznej, jak zbudować biznes. Absolwenci 
studiów innych kierunków, którzy uczestniczyli w badaniu, nie mieli możliwości wybrania przedmiotów dodatkowych, podczas których taką wiedzę można by nabyć. Wywiady częściowo standaryzowane niestrukturalizowane, które trwały od 70 do 90 minut każdy, przeprowadzono z dwoma mężczyznami i trzema kobietami. Najmłodszy rozmówca miał 36 lat. Trzech interlokutorów, każdy indywidualnie, prowadzi działalność krótkoterminowego wynajmu mieszkań. Połączyła ich jednak pasja do sztuki. Wspólnie uruchomili inicjatywę biznesową ArtTrip, która polega na organizowaniu projektów artystycznych i wystaw w przestrzeniach mieszkalnych. Jeden z pozostałych interlokutorów jest dyrektorem generalnym i założycielem MegaGen - podmiotu produkującego implanty, których dystrybucja odbywa się w ponad 60 krajach na świecie. Wywiad przeprowadzono także z dyrektorką jednego z działów MegaGen. Interlokutorzy przyznali, że kierunek studiów determinuje plan zajęć, a przekazywana wiedza często jest niewystarczająca z uwagi na brak aktualizacji treści kursu. Nie uczy się krytycznej analizy sytuacji, za mało, jeśli w ogóle, jest ćwiczeń praktycznych, nie wyzwala się także w studentach zachowań zespołowych, co wzmacniane jest choćby przez system oceniania studentów, który promuje konkurowanie. Przedsiębiorcy, absolwenci uniwersytetów, którzy założyli działalność gospodarczą, przyznają, że gros absolwentów kończy studia, idzie do pracy, gdzie zdobywa wiedzę, umiejętności czy buduje bazę klientów, po czym rezygnuje z miejsca pracy celem założenia działalności gospodarczej o podobnym profilu. Stąd, jak sami podkreślają, trudno znaleźć właścicieli przedsiębiorstw młodszych niż 30 lat. W raporcie dla OECD (Green 2013, s. 1) zaznaczono, że termin „młodzi” w kontekście bezrobocia odnosi się do ludzi poniżej 35. roku życia.

\section{Zakończenie}

Uniwersytety w Republice Korei mają kształcić wykwalifikowanych pracowników przygotowanych do podjęcia pracy, tworzyć wiedzę w drodze badań celem podniesienia poziomu inteligencji ludzi i rozwoju innowacji, które zmienią status quo na rynku, oraz przyczynić się do wzrostu poziomu opieki społecznej poprzez rozpowszechnianie wiedzy i innowacji w społeczeństwie. Kolejną rolą uniwersytetów stało się promowanie przedsiębiorczości i przedsięwzięć wysokich technologii. Oczekuje się z jednej strony wdrożenia i uruchomienia programów edukacji przedsiębiorczości, z drugiej komercjalizacji wiedzy i nowych technologii 
chociażby poprzez utworzenie podmiotów typu spin-off czy uzyskanie licencji (Bae i Park 2011, s. 114-115). Mimo to brakuje rozwiązań systemowych na poziomie edukacji. Każdy program przedsiębiorczości tworzony jest w odosobnieniu. Nie ma wskazanych kompetencji, które mają nabyć absolwenci. Problemem jest także kopiowanie rozwiązań biznesowych. Rozwój narzędzi cyfrowych i platform internetowych stworzył nowe szanse rynkowe dla przedsiębiorców, w szczególności prowadzących jednoosobową działalność gospodarczą. Eksport promowany jako skuteczne narzędzie wzrostu gospodarczego ugruntował w studentach intencje do zakładania działalności o zasięgu ponadnarodowym (Lee i in. 2006, s. 363), a narzędzia internetowe pozwalają im na nawiązanie relacji biznesowych na skalę globalną. MSP zajmują czołową pozycję $w$ handlu międzynarodowym przy wykorzystaniu narzędzi cyfrowych (OECD 2017a, s. 30). Kolejnym krokiem w polityce wzrostu jest podniesienie innowacyjności i kreatywności przedsiębiorców. 


\section{Bibliografia}

$\rightarrow 100$ Policy Tasks Five-year Plan of the Moon Jae-in Administration, August 17, 2017, Korean Culture and Information Service.

$\rightarrow$ Bae, Z., Park, S. (2011), University Technology Commercialization and Academic Entrepreneurship in Korea: The KAIST Experience [w:] P.K. Wong (red.), Academic Entrepreneurship in Asia: The Role and Impact of Universities in National Innovation Systems, Cheltenham: Edward Elgar Publishing, s. 108-134.

$\rightarrow$ Byun, C.G., Sung, C., Park, J., Choi, D. (2018), A Study on the Effectiveness of Entrepreneurship Education Programs in Higher Education Institutions: A Case Study of Korean Graduate Programs, "Journal of Open Innovation: Technology, Market, and Complexity", 4 (3), s. 26.

$\rightarrow$ Chang, C.H., Choi, S.H. (2018), A Study on Entrepreneurship Education and Entrepreneurial Intentions of Jewelry Design Majors in South Korea, „Journal of Engineering and Applied Sciences", 13, s. 2935-2940.

$\rightarrow$ Lee, S.M., Chang, D., Lim, S.B. (2005), Impact of Entrepreneurship Education: A Comparative Study of the U.S. and Korea, „International Entrepreneurship Management Journal", 1, s. 27-43.

$\rightarrow$ Lee, S.M., Lim, S.B., Pathak, R.D., Chang, D., Li, W. (2006), Influences on students attitudes toward entrepreneurship: A multi-country study , „Entrepreneurship Management", 2, s. 351-366.

$\rightarrow$ OECD (2017a), Entrepreneurship at a Glance 2017, Paris: OECD Publishing.

$\rightarrow$ OECD (2017b), How's Life? 2017: Measuring Well-being, Paris: OECD Publishing.

$\rightarrow$ Sahay, A., Sharma, V. (2008), Entrepreneurship and New Venture Creation, New Delhi: Excel Books. 


\section{Netografia}

$\rightarrow$ Green, F. (2013), Youth Entrepreneurship, www.oecd.org/cfe/leed/youth_bp_finalt.pdf (dostęp: 30.11.2018).

$\rightarrow$ KUBS (2014a), Startup Station, biz1.korea.ac.kr/en/node/43011 (dostęp: 26.11.2018).

$\rightarrow$ KUBS (2014b), [Undergraduate] Entrepreneurship Academy Program-based Scholarship, biz1.korea.ac.kr/en/undergraduate/notice/undergraduate-entrepreneurship-academy-program-based-scholarship (dostęp: 26.11.2018).

$\rightarrow$ OECD (2018a), Alcoholconsumption, data.oecd.org/healthrisk/alcohol-consumption.htm (dostęp: 22.11.2018).

$\rightarrow$ OECD (2018b), Suiciderates, data.oecd.org/healthstat/suicide-rates.htm (dostęp: 22.11.2018).

$\rightarrow$ Seoul Startup Hub (2017), Program, seoulstartuphub.com/eng/sub/program/ network.jsp (dostęp: 26.11.2018).

$\rightarrow$ SMBA, www.koisra.co.kr/en/partners/governmental.html (dostęp: 30.11.2018).

$\rightarrow$ Statista (2018), The most important statistics, www.statista.com/statistics/717996/south-korea-number-of-start-ups-by-business-age (dostęp: 26.11.2018). 